\title{
Velocity Amplification of Seismic Waves Through Parallel Fractures Near a Free Surface in Fractured Rock: A Theoretical Study
}

\author{
Ping Zhang ${ }^{1}$ (D) Ering Nordlund ${ }^{1} \cdot$ Graham Swan $^{2} \cdot$ Changping Yi $^{1}$
}

Received: 14 January 2018 / Accepted: 30 August 2018 / Published online: 5 September 2018

(c) The Author(s) 2018

\begin{abstract}
To determine the dynamic demand for support design under rockburst conditions, one of the most important issues is the prediction of ground motion parameters at the site of interest. Field monitoring has shown that the peak ground motion at the surface of an excavation in fractured rock is preferentially amplified compared to the motion in solid rock at a similar distance from the source. However, the traditional scaling laws used in rock support design do not account for the effect of free surface (excavation) and fracturing of rock. Recent studies have shown that high ground motion might be generated when a seismic wave crosses through fractures near a free surface in fractured rocks which is very complex and is not well understood. In this paper, particle velocity amplification was theoretically studied by investigating the dynamic interaction between seismic wave and multiple fractures near a free surface using the method of characteristics and the displacement discontinuity model. A harmonic load was applied on a model with a fractured zone near a free surface to investigate this phenomenon. After the harmonic wave propagated normally through multiple parallel fractures, the velocity amplification factor (VAF) was calculated as a function of the ratio of the magnitude of the peak particle velocity at the free surface of the model to the peak input velocity. The VAF can be as high as 3.77 and varies depending on the state of the fractured rock and the characteristics of the seismic wave. Parameter studies were conducted to investigate the effects of seismic load and multiple fractures on wave propagation, especially in terms of the wave frequency, the fracture spacing, the number of fractures and the stiffness of fractures. The results have proved that the interaction of the seismic wave and multiple fractures near the free surface strongly influences the ground motion. Quantitative relationships between the various influential factors and the corresponding VAF were developed. It is anticipated that such relationships can provide criteria to improve the current design procedures and help mining engineers to improve their rock support practice for rockburst-prone areas.
\end{abstract}

Keywords Rockburst $\cdot$ Velocity amplification $\cdot$ Fractured rock $\cdot$ Wave propagation $\cdot$ Free surface

\author{
Abbreviations \\ $f \quad$ Wave frequency $(\mathrm{Hz})$ \\ $j \quad$ Integer variable \\ $k \quad$ Specific stiffness of fractures $(\mathrm{Pa} / \mathrm{m})$
}

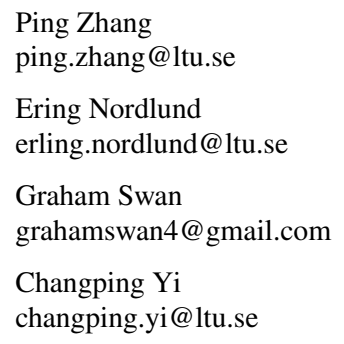

1 Division of Mining and Geotechnical Engineering, Luleå University of Technology, 97187 Luleå, Sweden

2 Rock Mechanics and Mine Design, Sudbury P3E 2X3, Canada
$L \quad$ Distance (m)

$n \quad$ Integer variable

$s \quad$ Fracture spacing $(\mathrm{m})$

$t \quad$ Time (s)

$\left|T_{1}\right|$ Transmission coefficient of seismic wave across a single fracture

$u \quad$ Particle displacement (m)

$v$ Particle velocity $(\mathrm{m} / \mathrm{s})$

$x \quad$ Position (m)

$Z \quad$ Seismic impedance $(\mathrm{Pa} \cdot \mathrm{s} / \mathrm{m})$

$\Delta l \quad$ Thickness between two adjacent layers (m)

$\Delta t \quad$ Time interval (s)

$\alpha \quad$ Compressional wave velocity ( $\mathrm{m} / \mathrm{s}$ )

$\varepsilon \quad$ Strain

$\lambda \quad$ Lame's constant

$\Lambda \quad$ Wavelength (m)

$\mu \quad$ Lame's constant 
$\xi \quad$ Non-dimensional fracture spacing

$\xi_{\text {cri }} \quad$ Critical non-dimensional fracture spacing

$\rho \quad$ Density $\left(\mathrm{kg} / \mathrm{m}^{3}\right)$

$\sigma \quad$ Stress (Pa)

$\omega \quad$ Angular frequency $(\mathrm{rad} / \mathrm{s})$

\section{Introduction}

Rockbursts, defined as damage to an excavation associated with a seismic event, are major hazards in deep underground mines. The majority of casualties are caused by the failure of the "skin" of the stope or tunnel (Durrheim et al. 1996). To mitigate the risk of seismically induced damage in deep underground mines, ground support is generally employed. The most widely used support design criterion under dynamic loading conditions is the energy-based design criterion, meaning the kinetic energy (plus potential energy if a gravity component is considered) of key rock blocks should be absorbed by a properly installed rock support system. Based on that criterion, the design methods for rock support were first proposed by Wagner (1984) and later improved by others such as Roberts and Brummer (1988) and Kaiser et al. (1996).

The kinetic energy is directly proportional to the mass of rock ejected and the square of the ejection velocity. A common assumption is that the rock ejection velocity is equal to the peak particle velocity (PPV) (Wagner 1984; Roberts and Brummer 1988). This assumption is based on the observation that the dominant wavelengths from remote seismic events are typically much longer than the tunnel or drift dimensions and that wave reflections can be ignored. These assumptions were confirmed by Yi and Kaiser (1993) with a theoretical evaluation of rock ejection from passing seismic waves by assuming rock as an elastic continuous medium and it showed that ejection velocities under typical mining and seismicity conditions (dominant frequencies less than about $100 \mathrm{~Hz}$ ) were less than, but close to the PPV. However, in most seismically active mines, the rock near the excavation surface is highly fractured and can not be simplified as an elastic continuous medium. The dynamic response of the fractured rock surrounding an excavation was poorly understood due to lack of cost-effective strong ground motion monitoring and recording systems in the past.

The amplification of wave motion of the walls of excavations was first observed and reported by Durrheim et al. (1996) at Blyvooruitzicht Gold Mine in South Africa. Peak velocity and acceleration parameters at the surface of an excavation were 4-10 times greater than that measured in the solid rock (Durrheim et al. 1996). Cichowicz et al. (2000) also reported that the peak ground motion is up to five-fold greater on the skin of the hanging wall than $6.5 \mathrm{~m}$ in the solid rock at Tau Tona Mine, South Africa. Later, extensive underground measurements of the PPVs were carried out at 58 sites at Tau Tona, Driefontein, Mponeng, Kloof, Harmony-Orkney, Harmony-Welkom and Bambanani gold mines in South Africa (Milev and Spottiswood 2005). Peak velocities measured on the skin of the excavations were found to be $9 \pm 3$ times on average higher than those in the solid rock inferred from the seismic data from all mines studied. The observed amplification is considerably greater than the two times amplification expected at a free surface. The effect is, additionally, although indirectly, confirmed by back analyses of ejection velocities of rock blocks which sometimes are of an order of $10 \mathrm{~m} / \mathrm{s}$ and greater (Ortlepp 1993; Stacey and Rojas 2013). In practice, the ejection velocity is sometimes approximately calculated by multiplying the incoming PPV with a site effect factor (i.e. velocity amplification factor). Considering the possible contribution of stored strain energy around an opening which can be transferred to the ejected rock, Kaiser et al. (1996) suggested an ejection velocity factor of between 1 and 4 . The site effect on velocity amplification has been quoted as about 2 or less in Western Australian hard rock mines, as the fracture zone is more likely to be less than a metre and rarely more than $2 \mathrm{~m}$ (Potvin et al. 2010). An average site effect factor of 3 was suggested for Long-Victor Mine, Australia by Mikula (2012) according to his experience. This effect is not well investigated, but amplification of the ground motion by a factor of up to 10 times is considered possible (Milev and Spottiswood 2005).

Different mechanisms have been suggested to explain the source for this phenomenon. Durrheim et al. (1996) explained that the amplification of the ground motion may be due to the resonance of fractured rock or the trapping of energy in the fractured rock around the excavation by multiple reflections and the generation of surface waves. Later in their another paper (Linkov and Durrheim 1998), they overrode the resonance explanation and stated resonance is not considered to be a likely mechanism as there is not sufficiently long periodic excitation during a seismic event. The hypothesis of trapping of energy was also questioned as it can not explain the fact that the amplification occurs both at surfaces with nearby cracks parallel and perpendicular to them. The common observation of slab buckling in the sidewalls of damaged excavations suggests that slab flexure may be the mechanism for causing high rock ejection velocities. Following its formation, McGarr (1997) proposed a mechanism of energy release due to slab buckling and explicitly derived an equation to calculate the ejection velocity. The buckling mechanism only considers the geometrical nonlinearity appearing in slab flexure, which ignores the physical nonlinearity of highly compressed rock. An alternative mechanism of energy release, which emphasises the role of softening at interacting surfaces of cracks or/and blocks was further proposed by Linkov and Durrheim (1998). The 
amplification due to physical nonlinearity at interacting softening surfaces is accounted for, but this mechanism only explains amplification in the frequency range above $5000 \mathrm{~Hz}$ for cracks with sizes of $0.2 \mathrm{~m}$ to $1.0 \mathrm{~m}$. The effect of amplification, observed in mines, usually occurs at a frequency of about $500 \mathrm{~Hz}$ or less which is an order less than the given estimate. In addition, buckling and softening occurs in a limit state, and hence the implication of the mechanisms applies to only stressed rock conditions. It might be an explanation in certain cases of stressed rock surrounding excavations, but it can not explain the ejection behaviour observed in unloaded conditions (Stacey and Rojas 2013). By explicitly coupling the fractures in the numerical model, Hildyard (2007) studied wave interaction with underground excavations in fractured rock and applied it to the rockburst problem in deep-level mining conditions. He concluded that fracturing and the excavation itself can provide explanation on this apparent amplification.

The effects of a single fracture on wave propagation were extensively investigated experimentally and theoretically using the displacement discontinuity model (PyrakNolte et al. 1990). Due to the complexity of multiple wave reflections between fractures, an approach was developed by combing the displacement discontinuity model and the method of characteristics to investigate the effects of multiple parallel planar fractures with linear deformable behaviour on normally incident one-dimensional wave attenuation by Cai and Zhao (2000). This approach was later adopted and further improved by Zhao et al. $(2006,2008)$ to investigate the $\mathrm{P}$-wave transmission across nonlinear deformable fractures and $\mathrm{S}$-wave transmission across parallel fractures with Coulomb slip behaviour. These studies have mainly focused on the prediction of wave attenuation across fractured rock masses. In fact, the fractures also amplify seismic wave when the fractures are located near a free surface. This has been observed by field monitoring (e.g. Durrheim et al. 1996; Cichowicz et al. 2000) and proved by numerical modelling (Zhang et al. 2015).

As the amplification of the ground motion is a critical and rather complex phenomenon and is affected by many factors, such as the presence of the free surface, fractured rock surrounding the excavations and the geometry of the excavation, as a first attempt, only the free surface and fracturing of rock are considered in this theoretical study. The velocity amplification was investigated using the method of characteristics and the displacement discontinuity model. The theoretical solution was obtained by solving a set of recurrence equations and considering the free surface boundary condition. The effects of fracture spacing, wave frequency, fracture stiffness and fracture number on the velocity amplification factor (VAF) were investigated with the help of the theoretical solutions. Quantitative relationships between various influential factors and the corresponding VAF were developed and a new approach to obtain VAF for improving support design under seismic conditions was proposed.

\section{Theory Background}

The theoretical two-dimensional model with a fractured zone near a free surface (right boundary) is illustrated in Fig. 1. The model was used to investigate the velocity amplification phenomenon at a free surface. The material is assumed to be unbounded to the top and bottom and the distance between the left and right boundary is far enough and hence the reflected wave from the right boundary will not superpose the incident wave at the left boundary. The fractures are assumed to be dry, planar, persistent and parallel. The incident seismic wave is assumed to be normal to the fractures as it causes the largest amplitude of the transmitted wave compared to an inclined incident seismic wave. As the motion of the material can only occur along one direction ( $x$ direction), it generates one-dimensional waves.

\subsection{Method of Characteristics}

The method of characteristics has been widely used in solving practical one-dimensional wave problems and also helps to explain the boundary and initial conditions that must be prescribed in such problems (Bedford and Drumheller 1994).

The one-dimensional wave equation is:

$\frac{\partial^{2} u}{\partial t^{2}}=\alpha^{2} \frac{\partial^{2} u}{\partial x^{2}}$,

where $u$ denotes the particle displacement of an elastic material, $\alpha$ denotes the compressional wave velocity, $x$ denotes the position and $t$ denotes the time. By introducing the following variables $v=\partial u / \partial t$ and $\varepsilon=\partial u / \partial x$, Eq. (1) can be re-written as a first-order equation

$\frac{\partial v}{\partial t}=\alpha^{2} \frac{\partial \varepsilon}{\partial x}$

where $v$ denotes the particle velocity and $\varepsilon$ denotes the strain. The variables $v$ and $\varepsilon$ are related by

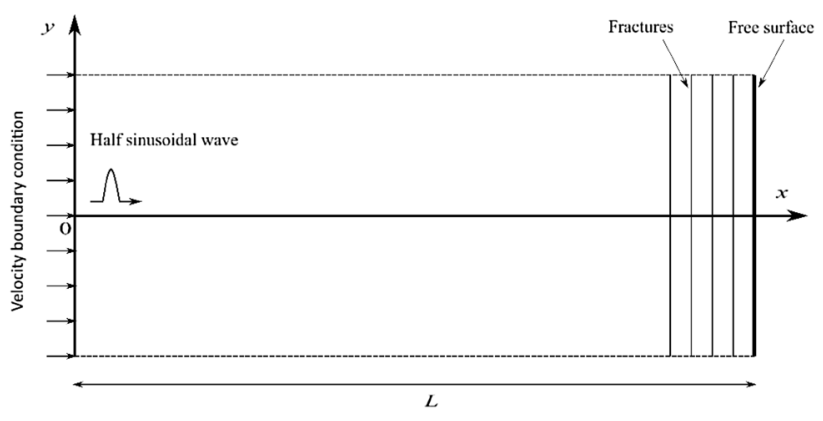

Fig. 1 Illustration of the theoretical model 
$\frac{\partial v}{\partial x}=\frac{\partial \varepsilon}{\partial t}$

Therefore, a system of two first-order equations, Eqs. (2) and (3), is obtained which can replace the second-order wave Eq. (1). Suppose that $v(x, t)$ and $\varepsilon(x, t)$ are the solutions of Eqs. (2) and (3) in the $x-t$ plane. The change in the quantity $v-\alpha \varepsilon$ from the point $x, t$ to the point $x+\mathrm{d} x, t+\mathrm{d} t$ is defined as:

$$
\begin{aligned}
\mathrm{d}(v-\alpha \varepsilon) & =\frac{\partial}{\partial t}(v-\alpha \varepsilon) \mathrm{d} t+\frac{\partial}{\partial x}(v-\alpha \varepsilon) \mathrm{d} x \\
& =\left(\frac{\partial v}{\partial t}-\alpha \frac{\partial \varepsilon}{\partial t}\right) \mathrm{d} t+\left(\frac{\partial v}{\partial x}-\alpha \frac{\partial \varepsilon}{\partial x}\right) \mathrm{d} x
\end{aligned}
$$

According to Eqs. (2) and (3), Eq. (4) can be re-written as

$\mathrm{d}(v-\alpha \varepsilon)=\left(\frac{\partial v}{\partial x}-\frac{1}{\alpha} \frac{\partial v}{\partial t}\right)(\mathrm{d} x-\alpha \mathrm{d} t)$.

The differential $\mathrm{d}(v-\alpha \varepsilon)$ is constant if

$\frac{\mathrm{d} x}{\mathrm{~d} t}=\alpha$

This means that the quantity $v-\alpha \varepsilon$ is constant along any straight line with slope $\alpha$ in the $x-t$ plane. Similarly, the quantity $v+\alpha \varepsilon$ is constant along any straight line with slope $-\alpha$ in the $x-t$ plane. The straight lines with slope $\alpha$ and $-\alpha$ in the $x-t$ plane are called the right-running and left-running characteristics of the one-dimensional wave equation.

The product of the seismic impedance $Z=\rho \alpha$ and the term $\alpha \varepsilon$ is

$Z \alpha \varepsilon=\rho \alpha^{2} \varepsilon=(\lambda+2 \mu) \frac{\partial u}{\partial x}=-\sigma$,

where $\sigma$ is the stress, $\rho$ is the density of the material, $\lambda$ and $\mu$ are the Lame's constants of the material. Note that this equation adopts the conventional geomechanics sign convention wherein the tensile stresses are considered to be negative and compressive stresses are positive.

Multiplying $v-\alpha \varepsilon$ and $v+\alpha \varepsilon$ by $Z$, the following relations are obtained:

$Z v+\sigma=$ constant

$Z v-\sigma=$ constant,

along the right-running and left-running characteristics, respectively.

Equations (8) and (9) have been widely used to analyse one-dimensional wave propagation normal to welded interfaces in layered media (Bedford and Drumheller 1994).

\subsection{Displacement Discontinuity Model}

The seismic response of a fracture is well-represented by the displacement discontinuity model (Pyrak-Nolte et al.
1990; Pyrak-Nolte 1996), i.e. a non-welded contact which is assumed to have negligible thickness compared to the seismic wavelength. A non-welded contact is treated as a displacement discontinuity, across which the stresses are continuous but the particle displacements and particle velocities are not. When an excavation is situated far from a seismic event, the magnitude of the stress wave when it reaches the excavation is generally too small to mobilize nonlinear deformation of the fractures, so linear fracture behaviour is assumed in the present study. The displacement across the non-welded contact is discontinuous by an amount inversely proportional to the specific stiffness of a fracture which can be expressed as:

$u_{2}-u_{1}=\frac{\sigma}{k}$

where $k$ is the specific stiffness of the fracture and subscripts 1 and 2 refer to the elastic materials on both side of the fracture. A physical analogue of the displacement discontinuity model is two elastic half-spaces coupled by springs, in which the fracture-specific stiffness is analogous to the spring constant per area for a set of distributed springs (Pyrak-Nolte 1996).

\subsection{One-Dimensional Wave Propagation Through Fractured Rock}

By combining the method of characteristics and the displacement discontinuity model, wave attenuation normally through multiple parallel fractures can be theoretically investigated (Cai and Zhao 2000). In fact, the approach is suitable for analyses of both P- and S-waves. The only difference is that different boundary conditions should be adopted when examining P- and S-waves. The normal stress, normal displacement and the corresponding normal stiffness of the fracture in Eq. (10) should be used when P-wave propagation is studied. Similarly, the shear stress, shear displacement and the corresponding shear stiffness of the fracture in Eq. (10) should be used when S-wave propagation is studied. In this paper, the derivation of wave propagation is demonstrated by $\mathrm{P}$-wave, but the theoretical results obtained from this study can be applied both for P- and S-waves.

Equations (8) and (9) representing the relations between $v$ and $\sigma$ are further derived to calculate the one-dimensional wave propagation normal to non-welded fractures by considering the displacement discontinuity model. Here, a general case is considered, meaning that different rock materials on the two sides of each fracture exist with seismic impedance $Z^{-}(n)$ and $Z^{+}(n)$. The stiffness of the $n$th fracture is represented as $k(n)$ and the spacing between every two adjacent fractures is set uniformly. In the $x-t$ plane, new independent variables $j$ and $n$ are imported and defined by: 
$j=\frac{t}{\Delta t}$

$n=\frac{x}{\Delta l}=\frac{x}{\alpha \Delta t}$

where $\Delta t$ is the time interval, $\Delta l$ is the thickness between two adjacent layers, $j$ and nare integer variables. A finite number of bonded layers with the left boundary of the first layer at $n=0$ and the right boundary of the last layer at $n=L / \Delta l$ ( $L$ is the distance between the left and right boundary) can be defined within the studied body. The interface between the layers could be fractures or welded interfaces, which can be treated as fractures with infinite fracture stiffness. It is assumed that the time interval $\Delta t$ can be chosen so that fractures only exist at integer values of $n$. According to Eqs. (11) and (12), right- and left-running characteristics meet at points defined by integral values of $j$ and $n$, as seen in Fig. 2. Particle velocities and stresses are calculated at these points.

With Eqs. (8) and (9), the relationships between the values of $v$ and $\sigma$ at the points shown in Fig. 2 can be obtained. Along right-running characteristic $a b$ and left-running characteristic $a c$ shown in Fig. 2, two relations can be built:

$Z^{-}(n) v^{-}(n, j+1)+\sigma^{-}(n, j+1)=Z^{-}(n) v^{+}(n-1, j)+\sigma^{+}(n-1, j)$,

$Z^{+}(n) v^{+}(n, j+1)-\sigma^{+}(n, j+1)=Z^{+}(n) v^{-}(n+1, j)-\sigma^{-}(n+1, j)$,

where $v^{-}(n, j+1)$ and $v^{+}(n, j+1)$ are particle velocities at time $j+1$ before and after the fracture at distance $n$, $\sigma^{-}(n, j+1)$ and $\sigma^{+}(n, j+1)$ are stresses at time $j+1$ before and after the fracture at distance $n$. Notice that $Z^{-}(n+1)$ is equal to $Z^{+}(n)$ which has been used when deriving Eqs. (13) and (14).

Based on the displacement discontinuity model, the two equations can be obtained:

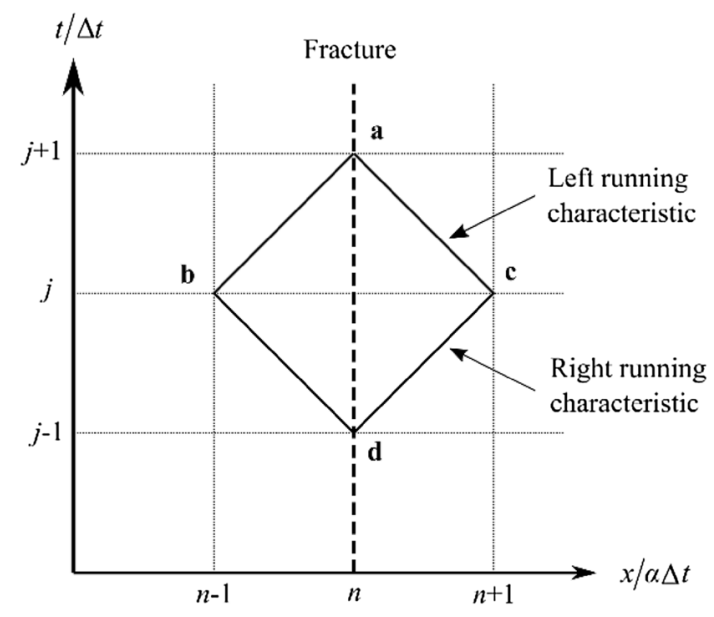

Fig. 2 Points corresponding to integer values of $j$ and $n$ in the $x-t$ plane (Modified after Bedford and Drumheller 1994)

$\sigma^{-}(n, j+1)=\sigma^{+}(n, j+1)=\sigma(n, j+1)$,

$u^{-}(n, j+1)-u^{+}(n, j+1)=\frac{\sigma(n, j+1)}{k(n)}$.

The derivative of Eq. (16) with respect to $t$ gives

$v^{-}(n, j+1)-v^{+}(n, j+1)=\frac{1}{k(n)} \frac{\partial \sigma(n, j+1)}{\partial t}$.

If $\Delta t$ is small enough, Eq. (17) can be expressed as

$v^{-}(n, j+1)-v^{+}(n, j+1)=\frac{1}{k(n)} \frac{[\sigma(n, j+1)-\sigma(n, j)]}{\Delta t}$.

Then Eq. (18) is re-written as

$\sigma(n, j+1)=\sigma(n, j)+\left[v^{-}(n, j+1)-v^{+}(n, j+1)\right] k(n) \Delta t$.

By solving Eqs. (13), (14) and (19), particle velocities and stress at point $a$ can be derived

$$
\begin{aligned}
v^{-}(n, j+1)= & \frac{Z^{+}(n)}{\left[Z^{+}(n) k(n) \Delta t+Z^{-}(n) k(n) \Delta t+Z^{+}(n) Z^{-}(n)\right]}\left\{v^{+}(n-1, j)\left[\frac{Z^{-}(n)}{Z^{+}(n)} k(n) \Delta t+Z^{-}(n)\right]\right. \\
& \left.+v^{-}(n+1, j) k(n) \Delta t+\sigma(n-1, j)\left[1+\frac{k(n) \Delta t}{Z^{+}(n)}\right]-\sigma(n, j)-\sigma(n+1, j)\left[\frac{k(n) \Delta t}{Z^{+}(n)}\right]\right\}, \\
v^{+}(n, j+1)= & \frac{Z^{-}(n)}{\left[Z^{+}(n) k(n) \Delta t+Z^{-}(n) k(n) \Delta t+Z^{+}(n) Z^{-}(n)\right]}\left\{v^{-}(n+1, j)\left[\frac{Z^{+}(n)}{Z^{-}(n)} k(n) \Delta t+Z^{+}(n)\right]\right. \\
& \left.+v^{+}(n-1, j) k(n) \Delta t+\sigma(n-1, j)\left[\frac{k(n) \Delta t}{Z^{-}(n)}\right]+\sigma(n, j)-\sigma(n+1, j)\left[1+\frac{k(n) \Delta t}{Z^{-}(n)}\right]\right\},
\end{aligned}
$$




$$
\begin{aligned}
\sigma(n, j+1)= & \sigma(n, j)+\frac{Z^{+}(n) Z^{-}(n) k(n) \Delta t}{\left[Z^{+}(n) k(n) \Delta t+Z^{-}(n) k(n) \Delta t+Z^{+}(n) Z^{-}(n)\right]}\left\{v^{+}(n-1, j)-v^{-}(n+1, j)\right. \\
& \left.+\sigma(n-1, j) \frac{1}{Z^{-}(n)}-\sigma(n, j)\left[\frac{1}{Z^{+}(n)}+\frac{1}{Z^{-}(n)}\right]+\sigma(n+1, j) \frac{1}{Z^{+}(n)}\right\} .
\end{aligned}
$$

To determine particle velocities and stresses at any point in the studied body, an iterative computation is needed to solve Eqs. (20), (21) and (22) by considering the boundary conditions. The initial conditions $v^{+}(n, 0), v^{-}(n, 0)$ and $\sigma(n, 0)$ must be specified. The calculations can be carried out in any order for all values of $n$, except $n=0$ and $n=L$. At the left boundary, $n=0$, Eq. (14) must be used and either $v^{+}(0,1)$ or $\sigma(0,1)$ must be specified. Similarly, at the right boundary, $n=L$, Eq. (13) must be used and either $v^{-}(L, 1)$ or $\sigma(L, 1)$ must be specified.

\section{Theoretical Model and Parameters}

\subsection{Model Description}

The theoretical model is illustrated in Fig. 1, in which a fractured zone is located near the right boundary. To facilitate the illustration, a dynamic load was normally applied at the entire left boundary of the model, and hence only a P-wave was generated and propagated through the model.

Fractures with regular spacing were located near the right boundary. The fractures were assumed to be dry, planar, persistent and parallel. It is assumed that all fractures had the same fracture stiffness. The incident seismic wave is assumed to be normal to the fractures as it causes the largest amplitude of transmitted wave compared to an inclined incident seismic wave. The dynamic load was expressed as time histories of particle velocity following a half-cycle sinusoidal function. Therefore, the boundary condition $v^{+}(0, j)$ was assigned at the left boundary $x=0$. The right boundary was free of restraint to simulate the real free surface and hence

Table 1 Parameters used in this study

\begin{tabular}{lll}
\hline & Unit & Value \\
\hline Density of rock material & $\mathrm{kg} / \mathrm{m}^{3}$ & 2800 \\
Young's modulus of rock material & $\mathrm{GPa}$ & 70 \\
$\begin{array}{l}\text { Poisson's ratio of rock material } \\
\text { Specific stiffness of fracture }\end{array}$ & $\mathrm{GPa} / \mathrm{m}$ & $5-1000$ \\
Fracture spacing & $\mathrm{m}$ & $0.05,0.1,0.3,0.5,1,2,4$ \\
Number of fractures & & $1,2,4,8,16,32,40$ \\
Wave frequency & $\mathrm{Hz}$ & $10-1000$ \\
\hline
\end{tabular}

the boundary condition at the right boundary $x=L$ was specified as stress $\sigma(L, j)=0$.

\subsection{Parameters}

The properties of the rock material adopted in the study were from LKAB's Kiirunavaara underground mine (Malmgren and Nordlund 2008) and are listed in Table 1. Even though the theoretical model can consider different rock materials between layers, homogeneous rock properties were used in this paper, meaning the seismic impedance was constant between layers, $Z^{-}(n)=Z^{+}(n)=Z$.

The ratio of the stress to displacement is called the specific stiffness of the fracture (interface) and it characterizes the elastic properties of a fracture (Pyrak-Nolte et al. 1990). Bandis (1980) investigated the effects of different rock types on normal stiffness of fractures including sandstones, siltstones, limestones, dolerites, and slates. For weathered, moderately weathered and fresh rocks, the average third cycle initial normal stiffness values of roughly 16 to $266 \mathrm{GPa} / \mathrm{m}$, correspond to effective normal stresses in the lowest possible range of 0-1 MPa. GomezHernandez and Kaiser (2003) investigated the influence of ground support on the magnitudes of "bulking" near excavation boundary and classified the ground support pressure for different types of ground support. The ground support pressure falls in the range of $0-0.5 \mathrm{MPa}$ from no support to heavy and strong support conditions. Within the fractured zone near an excavation boundary, the rock mass becomes a disintegrated assembly of fractured rock. The normal stress applied on the fractures could be as low as zero to several MPa and the normal fracture stiffness of fractures could be around ten to several hundred $\mathrm{GPa} / \mathrm{m}$. To cover a wide range of fracture stiffness, the values chosen for this investigation were in the range from 5 to $1000 \mathrm{GPa} / \mathrm{m}$.

For mining-induced seismicity problem, the rock mass near the excavation surface is very much fractured due to high in situ and mining-induced stresses. The fracture spacing in general is small and varies from several centimetres to tens of centimetres according to field investigation. The fracture spacing chosen in this study varied from 0.05 to $4 \mathrm{~m}$ considering the stress-induced fractures and naturally existing discontinuities. 
Potvin et al. (2010) reported that the fracture zone is more likely to be less than a metre and rarely more than $2 \mathrm{~m}$ for Western Australian hard rock mines. Simser (2012) suggested that the depth of the fractured zone could be assumed to be one-third of the excavation span. The span of a normal drift in most underground mines is equal or less than $7 \mathrm{~m}$. On the basis of the literature, the numbers of fractures chosen in this study are $1,2,4,8,16,32$ and 40 , which cover the depth of the fractured zone mentioned in the literature for different fracture spacings except the smallest fracture spacing, $0.05 \mathrm{~m}$.

Based on the investigation of seismic source parameters of typical mining-induced damaging seismic events, it is found that the corner frequency of seismic events falls into the range of $10-1000 \mathrm{~Hz}$ when the local magnitude is within the range of -2 to 3 . Different wave frequencies used in the modelling varied from 10 to $1000 \mathrm{~Hz}$ to cover the range reported. Since the focus of this work was to study how a seismic wave interacts with fractures and a free surface, the intrinsic material damping was ignored. In this case, the wave attenuation or amplification was only caused by the fractures and free surface. All of the parameters used in this study are listed in Table 1.

\subsection{Calibration of the Theoretical Model}

To obtain sufficient accuracy of the numerical results of $v^{-}(n, j+1)$ and $v^{+}(n, j+1)$, it is extremely important to choose a small time interval $\Delta t$ when computing Eqs. (20) and (21). However, a large amount of computation time is required when an extremely small time interval is used. According to Eq. (12), small time interval $\Delta t$ means small thickness $\Delta l$ between two adjacent layers. The effect of layer thickness $\Delta l$ has been investigated by Cai and Zhao (2000) by varying the layer thickness. By considering both computation efficiency and accuracy, $\Delta l=\Lambda / 100$ was suggested ( $\Lambda$ is the incident wavelength). However, the defined smallest fracture spacing was $0.05 \mathrm{~m}$ in this study. To examine such small fracture spacing, for a medium wave frequency of $100 \mathrm{~Hz}$, the layer thickness should be set as small as $\Delta l=\Lambda / 1120$ which was adopted in this paper. For wave frequency lower than $100 \mathrm{~Hz}$, extremely small layer thickness was chosen to consider the effect of smaller fracture spacing (e.g. $0.05 \mathrm{~m}, 0.1 \mathrm{~m}$ ).

The theoretical model and programming was then checked and calibrated by investigating two cases. The first case was to study the wave transmission across a single fracture. The fracture was then located in the middle of the model instead of near the free surface. The expression of transmission coefficient for normally incident one-dimensional wave propagating across a linearly deformable fracture is found in Eq. (23) (Pyrak-Nolte et al. 1990):

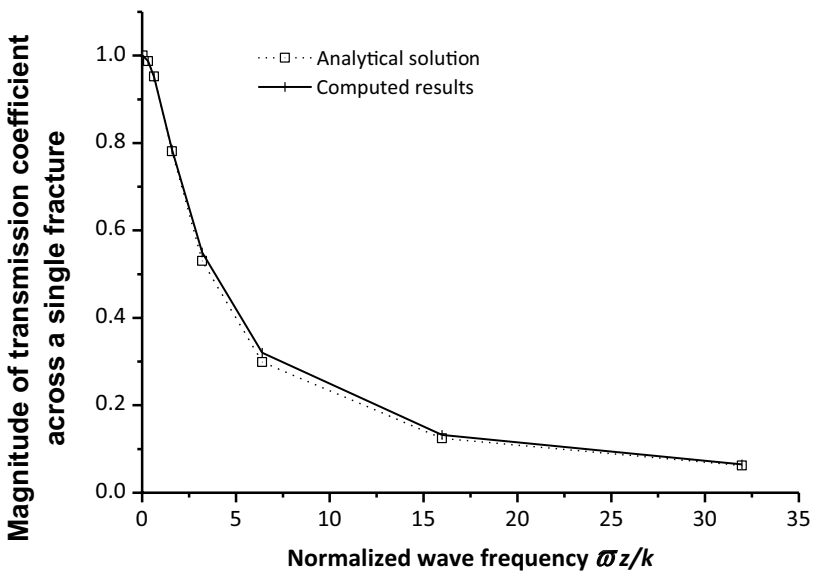

Fig. 3 Comparison between analytical solution and computational results of $\left|T_{1}\right|$

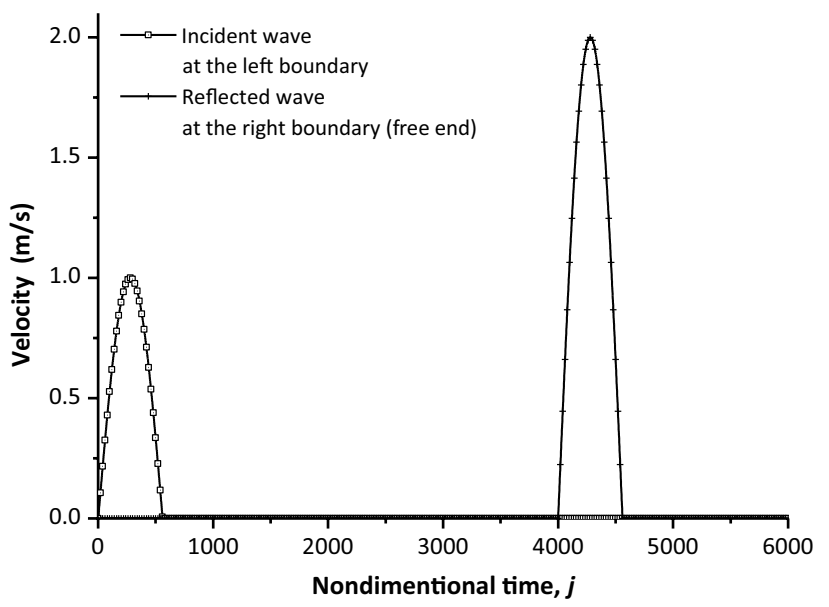

Fig. 4 Velocity-time curves for the incident wave at the left boundary and reflected wave at the right boundary (free surface)

$\left|T_{1}\right|=\left[\frac{4\left(\frac{k}{Z \omega}\right)^{2}}{4\left(\frac{k}{Z \omega}\right)^{2}+1}\right]^{1 / 2}$,

where $\left|T_{1}\right|$ is the transmission coefficient of seismic wave across a single fracture, $\omega$ is the angular frequency of the seismic wave. The magnitude of the transmission coefficient was then calculated after the wave had crossed the fracture. The comparison between computed result and analytical solution as a function of $\omega Z / k$ is presented in Fig. 3. It is found that the computed result shows good agreement with the analytical solution, meaning the theoretical model was derived correctly and the programming was well conducted.

The second case was to study the wave reflection at a free surface. It is known that when an incident compressive stress 
wave passes homogeneous, isotropic and elastic material and reaches a free surface normally, the wave is reflected as a tensile wave at the free surface. The reflected wave and the tail of the incident wave are then superimposed. The PPV at the free surface hence is doubled. The velocity amplification factor at the free surface then becomes 2 . Figure 4 shows the velocity-time curves defined at the left boundary and calculated at the right boundary (free surface) from the theoretical model. The computed velocity amplitude has been doubled at the free surface. Again, it is proved that the theoretical model was built correctly and the programme was working properly. The theoretical model was then used to study the velocity amplification of the seismic wave through parallel fractures near a free surface in a fractured rock.

\section{Results and Analyses}

The peak particle velocity (PPV) of ground motion has been widely accepted as the representative parameter for defining dynamic design load in rock support design (Kaiser and Maloney 1997). Therefore, only the peak particle velocity was analysed in this paper. The magnitude of the velocity amplification factor (VAF), defined as the ratio of wave amplitude at the free surface of the model and the applied incident wave amplitude was investigated.

The VAF at a free surface is 2 and is independent of wave frequency in homogeneous, isotropic and elastic rock. However, the VAF is not constant when the seismic wave propagates in a fractured rock mass. Zhang et al. (2015) investigated the wave amplification through numerical modelling and found that the degree of velocity amplification appears to be dependent on the frequency of the incident seismic wave, the fracture spacing, the fracture stiffness and the thickness of the fractured zone around an excavation, which were theoretically investigated in the following sections. To analyse the combined effect of fracture spacing and wavelength, a non-dimensional fracture spacing $\xi$ (the ratio of fracture spacing to incident wavelength) is used (e.g. Cai and Zhao 2000).

$\xi=\frac{s}{\Lambda}=\frac{s \cdot f}{\alpha}$,

where $s$ is the fracture spacing, $\Lambda$ is the incident wavelength and $f$ is the wave frequency.

When Pyrak-Nolte et al. (1990) studied the transmission of seismic waves across a single natural fracture, they found that the transmission and reflection coefficients of seismic waves depend on the specific stiffness of the fracture, the seismic impedance of the material and the frequency content of the signal, which can be expressed as the function of a normalized variable $\omega Z / k$. The frequency is then normalized by the ratio of the fracture

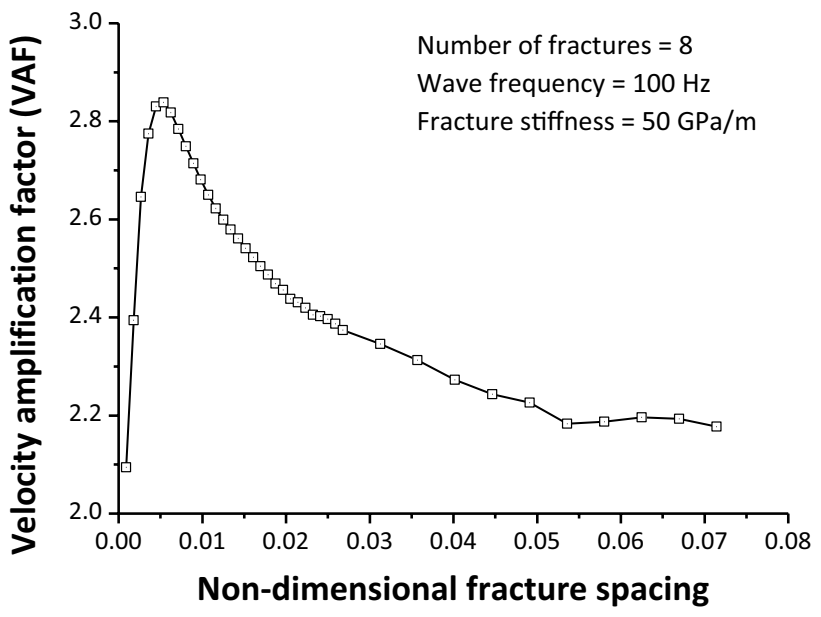

Fig. $5 \mathrm{VAF}$ as a function of non-dimensional fracture spacing

specific stiffness to the seismic impedance. To develop quantitative relationships between various influential factors and the corresponding VAF values, the normalized frequency and normalized fracture spacing were used in this study.

\subsection{Effect of Fracture Spacing on VAF}

Figure 5 shows the relationship between VAF and fracture spacing (expressed as the non-dimensional fracture spacing) when there are eight fractures in the fractured zone near the free surface. The fracture stiffness was 50 $\mathrm{GPa} / \mathrm{m}$ and the frequency of the incident wave was set as $100 \mathrm{~Hz}$. As can be seen from Fig. 5, the VAF values vary with the fracture spacing and are larger than 2 within the investigated parameter range. With the increase of fracture spacing, the VAF first increases quickly until it reaches a peak and then starts to drop slowly. A critical value $\left(\xi_{\text {cri }}\right)$ is defined in this paper at which the peak VAF appears. In this case, the critical non-dimensional fracture spacing $\xi_{\text {cri }}$ is 0.005 and the corresponding maximum $\mathrm{VAF}$ is 2.84

\subsection{Effect of Wave Frequency and Fracture Stiffness on VAF}

\subsubsection{Wave Frequency}

Figure 6 shows the VAF as a function of fracture spacing for different wave frequencies. The fracture stiffness was $100 \mathrm{GPa} / \mathrm{m}$ and the number of fractures in the model was eight. As seen in Fig. 6a, the curves end at different nondimensional fracture spacings within the studied fracture spacing ranges $(0.05-4 \mathrm{~m})$ using Eq. (24). It has to be 


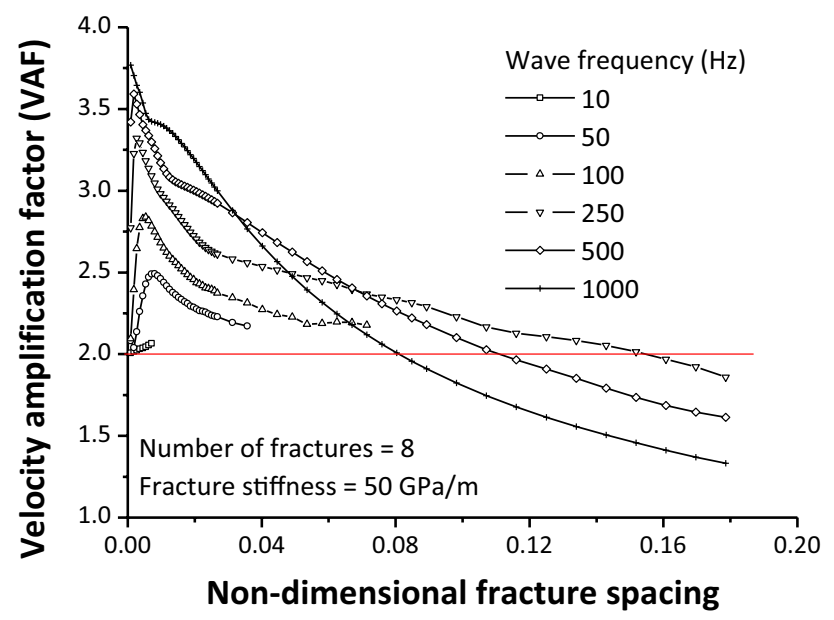

(a)

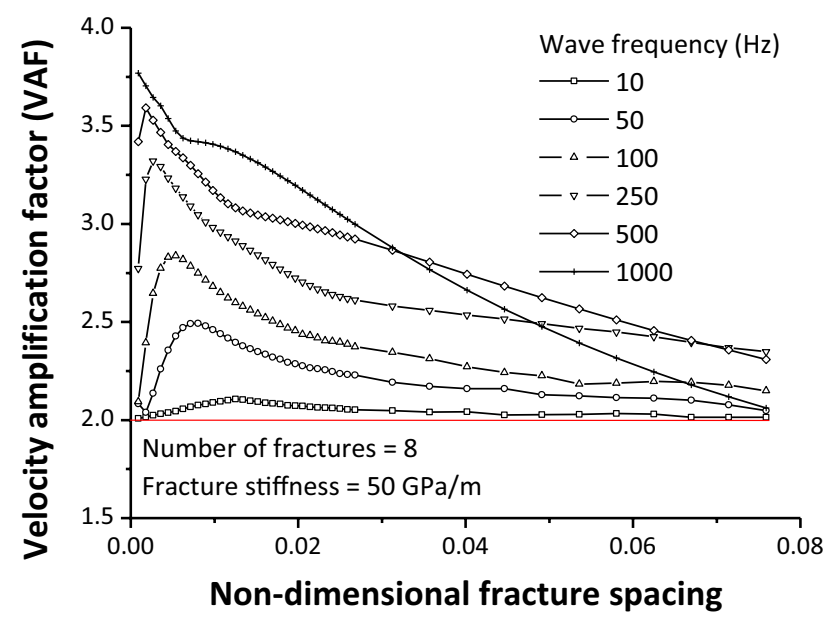

(b)

Fig. 6 VAF as a function of non-dimensional fracture spacing for different wave frequencies, a within the investigated fracture spacing range; and $\mathbf{b}$ with extra fracture spacing data

mentioned here, when the curves end for frequencies of 500 and $1000 \mathrm{~Hz}$, the corresponding fracture spacings are $2 \mathrm{~m}$ and $1 \mathrm{~m}$ which are smaller than the specified maximum fracture spacing of $4 \mathrm{~m}$. The reason is that the VAF is already lower than 2 for both cases indicating the wave attenuation is making major effect which is out of the scope of this paper. To facilitate the comparison, larger fracture spacings were also investigated for frequencies lower than $250 \mathrm{~Hz}$ and the curves with extra data are presented in Fig. 6b. To highlight the importance of velocity amplification and make the figure clearer, the non-dimensional fracture spacing is limited and less than 0.08 in Fig. $6 \mathrm{~b}$ and also in the following sections.

From Fig. 6, it is clear that the VAF as a function of nondimensional fracture spacing for different wave frequencies

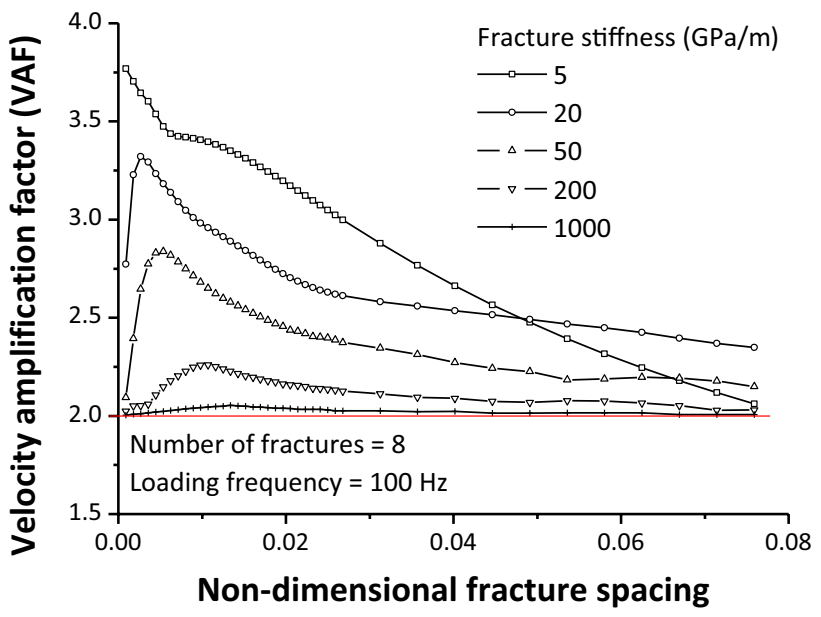

Fig. $7 \mathrm{VAF}$ as a function of non-dimensional fracture spacing for different fracture stiffness values

follows the same trend. The VAF first increases with the nondimensional fracture spacing and then reaches a peak value; after that, it starts to drop. However, the curve representing the variation of VAF with respect to non-dimensional fracture spacing presents different slopes for different wave frequencies. When the wave frequency is low, the slope of the curve is flat, indicating low sensitivity of the VAF with respect to the nondimensional fracture spacing. With the increase of the wave frequency, the slope of the curve becomes steeper, indicating that the VAF is very sensitive to the non-dimensional fracture spacing, especially for small values of the non-dimensional fracture spacing. Furthermore, when the non-dimensional fracture spacing is the same, the VAF is in general increasing with the wave frequency when the non-dimensional fracture spacing is less than 0.031 . When the non-dimensional fracture spacing is larger than 0.031 , the curves with higher wave frequencies (e.g. $1000 \mathrm{~Hz}$ ) drop quicker than those with lower wave frequencies and hence the VAF values for higher wave frequencies become lower than those of lower wave frequencies. When the non-dimensional fracture spacing is larger than 0.054 , the effect of wave frequency on VAF decreases. It is noted in Fig. 6a that the VAF becomes even lower than 2 when the non-dimensional fracture spacings are $0.161,0.107$ and 0.080 for the wave frequencies 250,500 and $1000 \mathrm{~Hz}$, respectively. In this case, the interaction of waves and fractures is much more complicated and the wave is largely attenuated when crossing multiple fractures.

The VAF reaches the highest value (3.77) when the wave frequency is $1000 \mathrm{~Hz}$ for the studied fracture stiffness, number of fractures and the range of the non-dimensional fracture spacing. The critical non-dimensional fracture spacing $\left(\xi_{\text {cri }}\right)$ decreases with the increasing wave frequency from $0.013(f=10 \mathrm{~Hz})$ to $0.0009(f=1000 \mathrm{~Hz})$. The corresponding fracture spacing decreases from 0.8 to $0.05 \mathrm{~m}$. It is noted 
that the peak of the curve does not appear when the wave frequency is $1000 \mathrm{~Hz}$ in the studied fracture spacing range indicating that the VAF could be even higher when the fracture spacing is smaller than $0.05 \mathrm{~m}$.

\subsubsection{Fracture Stiffness}

Figure 7 shows the VAF as a function of the non-dimensional fracture spacing for different fracture stiffness values. The frequency of the incident wave was set to $100 \mathrm{~Hz}$ and the fracture number in the model was 8 . As seen from Fig. 7, the variation trend between the VAF and the non-dimensional fracture spacing is quite similar for different fracture stiffness values. There is only one exception, for a fracture stiffness $5 \mathrm{GPa} / \mathrm{m}$. The peak value of the curve does not appear, and the VAF decreases with the increase of the non-dimensional fracture spacing within the studied parameter range. Again, the slope of the curves is different for different fracture stiffness values both in the ascent and descent stages indicating the VAF has different sensitivity to the non-dimensional fracture spacing. The higher the fracture stiffness value, the lower the sensitivity of VAF. For a fixed non-dimensional fracture spacing, the VAF decreases with increasing fracture stiffness except for fracture stiffness $5 \mathrm{GPa} / \mathrm{m}$ after the curve intersects the others. The critical non-dimensional fracture spacing $\left(\xi_{\text {cri }}\right)$ increases with increasing fracture stiffness. When the fracture stiffness is higher than $1000 \mathrm{GPa} / \mathrm{m}$, the effect of fractures diminishes and the VAF is almost constant with respect to the non-dimensional fracture spacing.

\subsubsection{Normalized Wave Frequency}

When comparing Figs. $6 \mathrm{~b}$ and 7 , it is worth noting that some of the curves are showing the same values at different wave frequencies and fracture stiffness values. For example, the

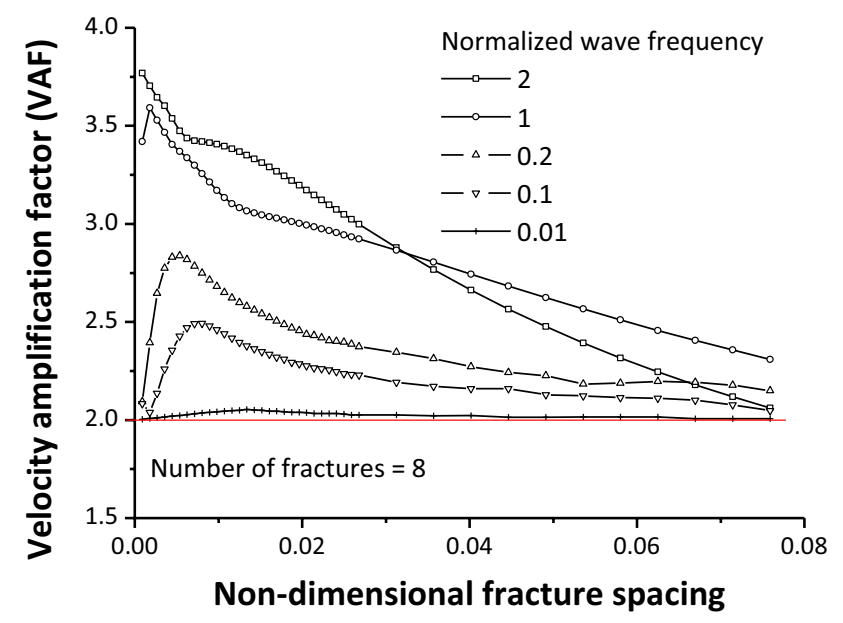

Fig. 8 VAF as a function of non-dimensional fracture spacing for normalized wave frequencies curve in Fig. $6 \mathrm{~b}$ where the fracture stiffness is $50 \mathrm{GPa} / \mathrm{m}$ and the wave frequency is $1000 \mathrm{~Hz}$ is the same as the curve in Fig. 7 where the fracture stiffness is $5 \mathrm{GPa} / \mathrm{m}$ and the wave frequency is $100 \mathrm{~Hz}$. Using the variable $\omega Z / k$, the wave frequency can then be normalized by defining the ratio of the product of the angular frequency of the seismic wave and the seismic impedance of rock to the fracture specific stiffness. Therefore, the combined effect of wave frequency and fracture stiffness on VAF can be investigated.

Figure 8 shows the VAF as a function of fracture spacing for different normalized wave frequencies $\omega Z / k$. The fracture number was set to 8 . When the normalized wave frequency is low (in this case, lower than 0.01), the VAF is almost constant and close to 2 within the studied parameter range, meaning that the effect of the fractured zone with high fracture stiffness on low frequency waves is almost negligible near a free surface. With the increase of normalized wave frequency $\omega Z / k$, the VAF in general is increasing especially when the non-dimensional fracture spacing is small, but the corresponding critical non-dimensional fracture spacing $\left(\xi_{\text {cri }}\right)$ is decreasing. This means that when a high frequency wave crosses multiple fractures with low fracture stiffness near a free surface, it can cause large wave amplification especially when the fracture spacing is small.

\subsection{Effect of Fracture Number on VAF}

Since the fractures in the theoretical model were located near a free surface with a regular spacing, the thickness of the fractured zone was proportional to the number of fractures when the fracture spacing was kept constant. Therefore, the effect of the thickness of the fractured zone can also be studied by investigating the effect of fracture number. The VAF as a function of fracture spacing for a different number of fractures is shown in Fig. 9a-c when the normalized wave frequencies $\omega Z / k$ was set to $0.01,0.1$ and 1 .

The change of fracture numbers did not change the trend of the VAF as a function of non-dimensional fracture spacing. In general, the VAF first increases and then decreases with the increase of fracture spacing. When fracture spacing is fixed, it is obvious that the VAF increases with the increase of fracture numbers especially when the non-dimensional fracture spacing is small. This relationship changes with the increase of the non-dimensional fracture spacing, becoming obvious when the normalized wave frequency is higher than 1 (see Fig. 9c). The maximum VAF is obtained for the maximum number of fractures but then it drops sharply with the increase of the non-dimensional fracture spacing and becomes even lower than that for small fracture numbers. This indicates that wave attenuation dominates when passing multiple fractures with larger spacing. When the non-dimensional fracture spacing is larger than 


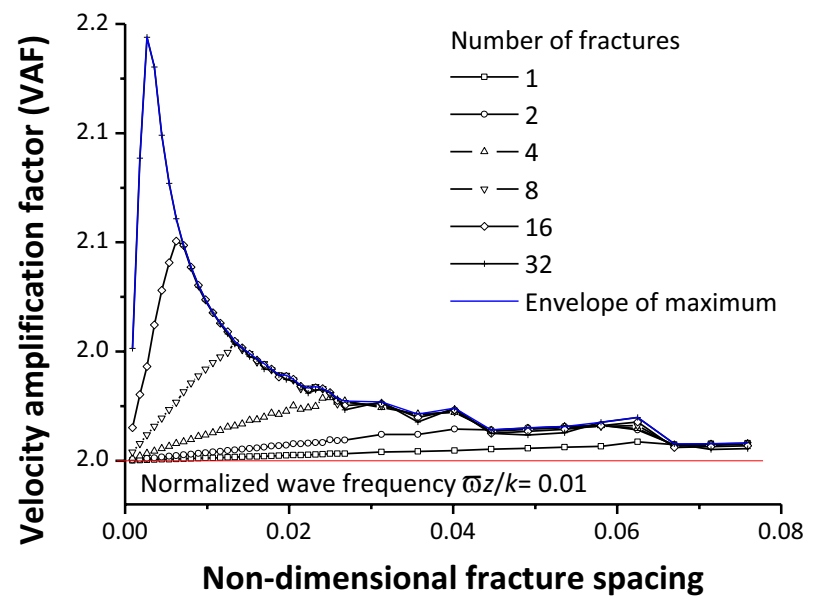

(a)

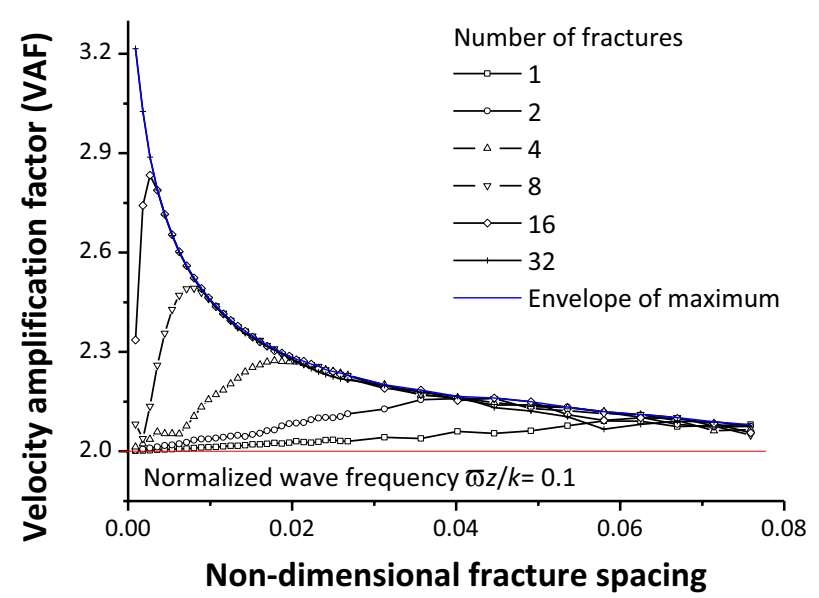

(b)

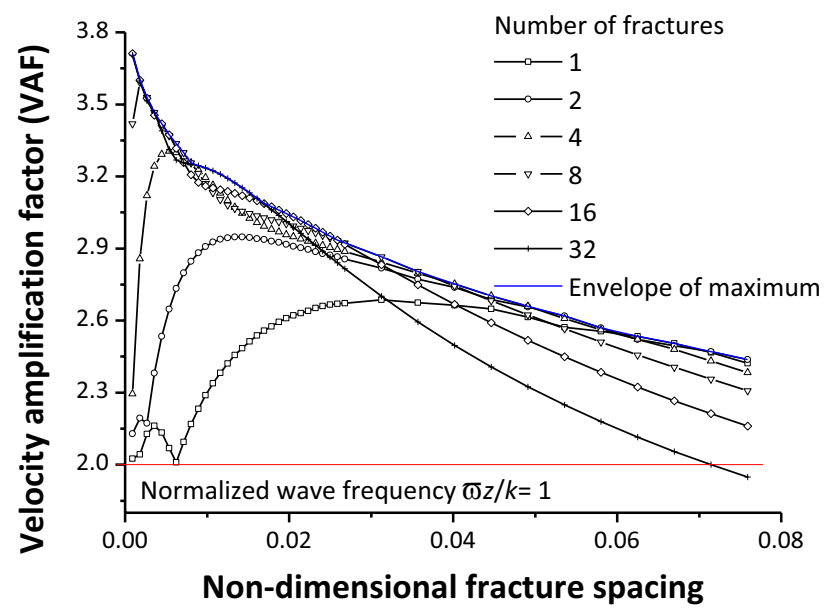

(c)

Fig. $9 \mathrm{VAF}$ as a function of non-dimensional fracture spacing for different number of fractures. The normalized wave frequencies $\omega Z / k$ were set as about a $0.01, \mathbf{b} 0.1$ and $\mathbf{c} 1$

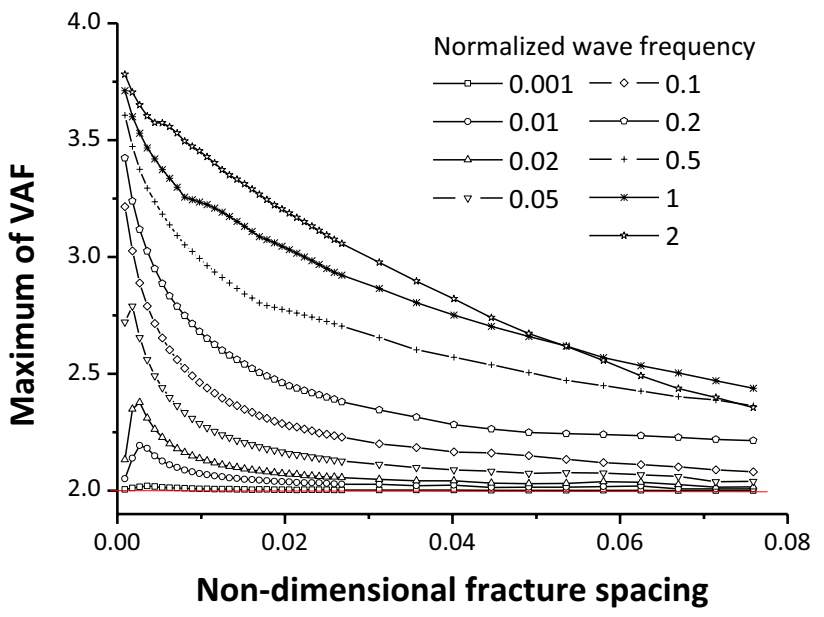

Fig. 10 Maximum of VAF as a function of non-dimensional fracture spacing for different normalized wave frequencies

0.067, the effect of fracture numbers on wave amplification can be ignored within the investigated parameter range.

With the increase of fracture numbers, the shape of the curves changes gradually. When the fracture number is small, the curve is flat; when fracture number is large, the curve becomes steep. This means that the VAF is sensitive to fracture spacing when the fracture number is large, especially for small non-dimensional fracture spacing. The critical value of the non-dimensional fracture spacing $\left(\xi_{\text {cri }}\right)$ for each curve decreases with increasing fracture number. For example, the critical non-dimensional fracture spacing $\left(\xi_{\text {cri }}\right)$ drops from 0.116 for 1 fracture to 0.003 for 32 fractures when the normalized wave frequency is 0.01 .

To find a maximum value within the studied range of fracture numbers, an envelope of maximum VAF is plotted in Fig. 9 as a solid blue line. It seems that the maximum VAF follows the curve of the largest number of fractures when the normalized fracture spacing is small and when the normalized wave frequency is low. With the increase of the normalized wave frequency, the envelope of maximum VAF first follows the curves of the largest number of fractures and then the lower number of fractures.

\subsection{Selection of VAF}

In rock support design under rockburst conditions, it is important to consider the velocity amplification of the seismic wave when it approaches an excavation surface. However, it is very difficult to determine the number of fractures within the fractured zone behind the excavation surface. Rockburst statistics show that $90 \%$ of the rockburst fatalities occurring in Ventersdorp Contact Reef and Carbon Leader Reef stopes were caused by rock falls less with a thickness of $1.6 \mathrm{~m}$ (Roberts 1995). For a typical 
$5 \mathrm{~m}$ by $5 \mathrm{~m}$ underground drift, the maximum depth of the fractured zone can be assumed to be $1.6 \mathrm{~m}$ (Simser 2012) and the minimum fracture spacing can be assumed to be $0.05 \mathrm{~m}$, so that the maximum number of fractures within the fractured zone is 32 which has been investigated in this study. By looking at the curves in Fig. 9, the envelope of the maximum of VAF could be obtained for each normalized wave frequency and it is redrawn in Fig. 10.

Figure 10 shows the maximum of VAF as a function of non-dimensional fracture spacing for different normalized wave frequencies. The combined effects of fracture spacing, number of fractures, fracture stiffness and wave frequency are all considered using the maximum VAF and normalized variables in Fig. 10. Therefore, the chart obtained can be referred for selection of VAF for designing rock support under seismic conditions.

Using the chart proposed in Fig. 10, the procedure for selection of VAF in rock support design is listed as follows:

1. Define the corner frequency of a designed seismic event for an acceptable probability of occurrence or a desired confidence level.

2. Assess the average fracture stiffness and average fracture spacing of the fractured rock or natural discontinuities near a designed excavation boundary.

3. Calculate the normalized wave frequency using the defined corner frequency and the assessed fracture stiffness. Select the curve corresponding to the normalized wave frequency in Fig. 10.

4. Calculate the non-dimensional fracture spacing and use the selected curve to obtain the required value for VAF.

As fracture stiffness, fracture spacing and corner frequency normally fall into ranges, it is also possible to use the chart to get the range of the designed VAF. It should be noted that the chart gives the maximum value for VAF at specified variables, therefore, the obtained VAF using this method might give the upper limit of the actual VAF.

\section{Discussion}

\subsection{Interaction of Wave and Multiple Fractures}

It is known that the presence of fractures affects the wave propagation. In most cases, the wave is attenuated by multiple fractures when it crosses through fractured rock masses. In rock engineering applications, there is a great concern about how much a seismic wave is attenuated after crossing a fractured rock mass. As a consequence, many researchers have studied wave propagation through multiple fractures using laboratory, theoretical, and numerical methods.
When fracture spacing is large and wave frequency is high enough, i.e. large $\xi$, the effect of multiple reflections between fractures on wave amplitude can be ignored. Multiple fractures hence behave as a damper and the wave is normally attenuated. However, when $\xi$ is small, for small fracture spacing and relatively low wave frequency problem, the wave superposition of transmitted waves caused by inter-fracture reflections becomes strong. The magnitude of velocity for a transmitted wave across parallel fractures in some cases might be higher than that of the incident wave (Zhao et al. 2008). Furthermore, when the wave meets the free surface, the reflected wave and the tail of the incident wave are superimposed at the free surface, which causes great amplification of the peak particle velocity.

Using a theoretical model with a fractured zone simulated explicitly, the interaction of wave and multiple fractures near a free surface was investigated theoretically. Velocity amplification has been proved by the theoretical model. The highest velocity amplification factor (VAF) obtained in this study is 3.77 but the result was obtained within the studied parameters range. As can be seen from the analysis (Figs. 6, 7, 8), the peak of VAF did not appear for some curves within the studied parameter range, meaning even higher VAF is possible for some cases (e.g. higher frequency, smaller fracture spacing, lower fracture stiffness, more fracture numbers). It also tells us that the VAF is site-specific.

The approach adopted in this study was to focus on the velocity at the free surface of the model resulting from the superposition of multiple reflected and transmitted waves, regardless of the detailed process of wave superposition.

\subsection{Influential Factors on VAF}

Based on the theoretical analysis, it is found that VAF is influenced by many factors, including fracture stiffness, fracture spacing, fracture number (thickness of fractured zone) and wave frequency. The dependence of VAF on fracture spacing is governed by the ratio $(\xi)$ of fracture spacing to the incident wavelength. A critical value $\left(\xi_{\text {cri }}\right)$ is also identified. When $\xi<\xi_{\text {cri }}$, the velocity amplification factor increases with increasing $\xi$. When $\xi>\xi_{\text {cri }}$, the VAF decreases with increasing $\xi$. The critical value $\left(\xi_{\text {cri }}\right)$ increases with increasing fracture stiffness, decreasing wave frequency and decreasing fracture number within the investigated parameters range.

By defining a normalized wave frequency, the combined effects of wave frequency and fracture stiffness on VAF have been considered. With the increase of normalized wave frequency $\omega Z / k$, the VAF in general is increasing, especially when the non-dimensional fracture spacing is small, but the corresponding critical non-dimensional fracture spacing $\left(\xi_{\text {cri }}\right)$ is decreasing. For a typical fracture stiffness (e.g. 50 $\mathrm{GPa} / \mathrm{m}$ ) of rock mass, it has been found that the VAF has a higher value for a large range of fracture spacing when the 
wave frequency falls within the range of $100-500 \mathrm{~Hz}$ (see Fig. 6). Even though the highest VAF value could appear when wave frequency is higher than $500 \mathrm{~Hz}$, it drops quickly with the increase of fracture spacing. Furthermore, a high frequency wave is subjected to material damping which has not been considered in this study, and hence it could be anticipated that the actual VAF at a high wave frequency situation can be lower than that calculated from the theoretical model. Therefore, a strong amplification in general could occur when wave frequency falls into the range from about 100 to $500 \mathrm{~Hz}$ for a common fractured rock condition. As this frequency range is influenced by fracture stiffness, fracture spacing and number of fractures, the exact value can only be determined based on the field investigation and it is possible that the actual figure is beyond the range.

Durrheim et al. (1996) observed resonances at the frequencies in the range of $400-1000 \mathrm{~Hz}$ based on the field measurement at Blyvooruitzicht Gold Mine. Cichowicz et al. (2000) revealed that strong resonances appear around $160 \mathrm{~Hz}$ and in the range of $200-300 \mathrm{~Hz}$ after analyzing the changes in signal properties between hanging wall geophones installed at Tau Tona Mine in South Africa. Later, Cichowicz (2001) analysed a set of data from Mponeng and East Driefontein Mines and further stated that no resonance was observed in the frequency range from 10 to $100 \mathrm{~Hz}$, hence site amplification does not take place within frequency bands controlled by the dominant signal of large seismic events. Durrheim (2012) concluded that the site amplification factor depends on wavelength, with a maximum amplification factor for a wavelength of about $30 \mathrm{~m}$, which corresponds to the wave frequency of $150-200 \mathrm{~Hz}$ assuming a P-wave velocity of $4500-6000 \mathrm{~m} / \mathrm{s}$. These observations have been helpful in supporting the conclusion drawn from this theoretical study regarding the effect of wave frequency.

For a constant wave frequency, the VAF decreases with increasing fracture stiffness and it approaches 2 when fracture stiffness is extremely high (larger than $1000 \mathrm{GPa} / \mathrm{m}$ ). When the fractures have lower fracture stiffness, multiple reflections between the fractures become stronger and hence promote the wave superposition. Therefore, the VAF near the free surface becomes higher. When the fractures have higher fracture stiffness, there is less reflection between the fractures and hence wave superposition becomes weaker. When the fracture stiffness approaches infinity, the fracture behaves as a welded boundary and hence no reflection occurs on the fracture boundary. The fractured zone hence behaves as a homogeneous and isotropic rock, and the wave only reflects at the free surface and the velocity amplitude of the wave just gets doubled.

Cichowicz et al. (2000) stated that ground support system applied on excavations influences the site amplification. One of the reasons could be because support system has affected the development of fractures near excavations and also increases the fracture stiffness by reinforcing and providing confinement on the fractured rock. In fact, the observed vibrations of ground support suggest that some portion of impacted energy into the ground support will be returned to the surrounding rock, which implies that only a fraction of the strong ground motion energy imparted to a support unit is absorbed through permanent deformation (Cichowicz 2001; Shirzadegan et al. 2016). The percentage of energy transferred to rock support under seismic conditions is dependent on the state of fractured rock. If the rock is less fractured, most of the energy could be transferred back to the surrounding rock. Therefore, to reduce the site amplification and lower the energy transferred to ground support under dynamic loading conditions, strong and stiff support system might be helpful and even better than weak and deformable support which allows fracture development. However, this idea is proposed from wave amplification and energy transfer point of view. It has to be applied with care as to certain extent deformable support system has to be used to handle large deformation and absorb the kinetic energy from loose rock block due to its advantage of larger energy absorption and deformation capacities.

\subsection{VAF and its Application in Rock Support Design}

When designing rock support in burst-prone ground, the dynamic demand on the rock support is most often expressed in terms of kinetic energy which is a function of the mass in motion and the ejection velocity at which the mass is moving. If a rock ejection is caused by a remote seismic event and the kinetic energy is transferred from the event, according to the Rockburst Support Handbook (Kaiser et al. 1996), the key steps in assessing the ejection velocity for a particular area in a mine are:

- Examine the seismicity records at the mine to establish the spatial and temporal distributions of seismic events;

- Choose a location of a design event;

- Select a design magnitude for the seismic event;

- Select appropriate scaling law parameters for predicting the PPV and hence, the ejection velocity.

In the last step, the value of the ejection velocity is assumed to be equal to PPV. However, the particle velocity is affected by local features such as the intensity of fracturing, and the zone of influence of support elements near excavations, which is called site effect (Cichowicz et al. 2000). By explicitly considering a fractured zone and a free surface in the theoretical model, the site effect was investigated quantitatively and a VAF chart was proposed in this paper. As the scaling law approach for PPV estimation is a semi-empirical approach and it assumes 
that the ground is isotropic and not dominated by internal discontinuities causing strong reflections (Kaiser and Cai 2013) and it does not consider the effect of the excavation surface, it needs to be combined with the VAF chart when used in rock support design incorporating the effects of velocity amplification. The PPV at the free surface of an excavation can be expressed as

$\mathrm{PPV}_{\text {Surface }}=\mathrm{PPV}_{\mathrm{SL}} \cdot \mathrm{VAF}$,

where $\mathrm{PPV}_{\text {Surface }}$ is the peak particle velocity at the free surface, $\mathrm{PPV}_{\mathrm{SL}}$ is the peak particle velocity calculated using the traditional scaling laws.

In addition, PPV alone has been challenged as being a good predictor for seismic damage estimation (Cichowicz et al. 2000) or a suitable parameter for rock support design (Mikula 2012) as it ignores significant factors such as wave frequency and the fractured zone near the excavation surface. Using the chart in Fig. 10, the combined effects of fracture spacing, number of fractures (depth of fractured zone), fracture stiffness and wave frequency on the velocity amplification are considered. As there is still lack of a better alternative to PPV for rock support design, it is wise to combine the $\mathrm{PPV}_{\mathrm{SL}}$ calculated using the traditional scale laws and the VAF, as a first step, to account for the most significant influential factors on velocity amplification at the free surface of an excavation.

As this theoretical model only examines the one-dimensional motion of the material, the effect of the excavation geometry, regional support systems such as pillars and backfill on velocity amplification, which is called structural effect (Cichowicz et al. 2000), was not considered in this paper. Furthermore, the fracture deformation was described by a linearly elastic model in this study, but the complete deformational behaviour of rock fractures is generally nonlinear. The fracture stiffness could be low when they are initially compressed under compressive seismic wave loading and then increase with the increase of contact stresses. The nonlinear deformational behaviour of fractures was not investigated in this study.

As an initial study, the theoretical chart proposed for estimating the velocity amplification could be used for local seismic hazard assessment and rock support design in rockburst conditions, especially where the rock support is designed to prevent damage from remote seismic events. Since the theoretical model is developed using simplifications, there are limitations of the results as mentioned above. A two-dimensional and a three-dimensional numerical model are going to be constructed to investigate the combined effects of free surface, fractures with various orientations, geometry of an excavation and ground support. In addition, a comprehensive field monitoring programme has been started, and field data have been collected and is under investigation (Zhang et al. 2016). The chart will be further improved after the numerical models are calibrated using the collected field data.

\section{Conclusions}

Velocity amplification was theoretically investigated in this paper using the method of characteristics and the displacement discontinuity model. The dynamic interaction between fractured rock and a free surface was studied using the theoretical model. The results have shown that the interaction of the seismic wave, free surface and fractured zone near the free surface strongly influences the ground motion and the particle velocity at the free surface of the theoretical model can be amplified compared to the incident wave amplitude. The main factors affecting the velocity amplification are wave frequency, fracture stiffness, fracture spacing and fracture numbers (thickness of fractured zone).

The velocity amplification factor (VAF), defined as the ratio of the wave amplitude at the free surface of the theoretical model and the incident wave amplitude, has been studied. Various parameters in a real environment have been chosen and the normalized variables have been investigated. Quantitative relationships between the various influential factors and the corresponding VAF were developed. The VAF can be as high as 3.77 within the studied parameter range.

As a consequence, the velocity amplification phenomena should be taken into account during the assessment of the local seismic hazard and rock support performance, especially where the rock support is designed to prevent damage from remote seismic events. Using the theoretical model to investigate the response of fractured rock from a remote seismic event, the authors proposed a new approach to obtain VAF for improving support design under seismic conditions. The relationships between the VAF and the normalized influential parameters and the procedure to select VAF were summarized and presented. As there is still lack of a better alternative to PPV for rock support design, it is wise to combine the $\mathrm{PPV}_{\mathrm{SL}}$ calculated using the traditional scale laws and the VAF, as a first step, to account for the most significant influential factors on velocity amplification. It is anticipated that such relationships can provide criteria to improve the current design procedures and help mining engineers to improve their rock support practice for rockburst-prone areas.

Acknowledgements The authors gratefully acknowledge the financial support from the strategic innovation programme for the Swedish Mining and Metal Producing Industry (STRIM), which is a joint investment from VINNOVA (The Swedish Governmental Agency for Innovation Systems), the Swedish Energy Agency and Formas with additional funding from Lundin Mining, LKAB, and Boliden (Ref. No.: 201401944, 2017-02228). This work was also partly supported by MIGS II-III (Mining Initiative on Ground Support Systems and Equipment) 
consortium and Centre of Advanced Mining and Metallurgy (CAMM) at Luleå University of Technology which are gratefully acknowledged. $\mathrm{LKAB}$ is specially acknowledged for providing funding for the first author to conduct research in this area.

Open Access This article is distributed under the terms of the Creative Commons Attribution 4.0 International License (http://creativeco mmons.org/licenses/by/4.0/), which permits unrestricted use, distribution, and reproduction in any medium, provided you give appropriate credit to the original author(s) and the source, provide a link to the Creative Commons license, and indicate if changes were made.

\section{References}

Bandis S (1980) Experimental studies of scale effects on shear strength, and deformation of rock joints. PhD thesis, University of Leeds, England, p 385

Bedford A, Drumheller DS (1994) Introduction to elastic wave propagation. Wiley, Chichester, pp 68-82

Cai JG, Zhao J (2000) Effects of multiple parallel fractures on apparent attenuation of stress waves in rock masses. Int J Rock Mech Min Sci 37:661-682

Cichowicz A (2001) The meaningful use of peak particle velocity at excavation surface for the optimisation of the rockburst support criteria for tunnels and stopes. Final report GAP709b, safety in mines research advisory committee, Johannesburg, p 33

Cichowicz A, Milev AM, Durrheim RJ (2000) Rock mass behaviour under seismic loading in a deep mine environment: implications for stope support. J S Afr Inst Min Metall 100(2):121-128

Durrheim RJ (2012) Functional specifications for in-stope support based on seismic and rockburst observations in South African mines. In: Potvin Y (ed) Proceedings of the 6th international seminar on deep and high stress mining, Perth, Australia, 28-30 March, Australian Centre for Geomechanics, Perth, Australia, pp 173-187

Durrheim RJ, Kullmann DH, Stewart RD et al (1996) Seismic excitation of the rock mass surrounding an excavation in highly stressed ground. In: Aubertin M, Hassani F, Mitri H (eds) Proceedings 2nd North American Rock mechanics symposium, Montreal, Quebec, Canada, 19-21 June, Balkema, Rotterdam, pp 389-394

Gomez-Hernandez J, Kaiser PK (2003) Modeling rock mass bulking around underground excavations. In: Proceedings of 10th ISRM congress on rock mechanics, SAIMM, Johannesburg, pp 389-395

Hildyard MW (2007) Wave interaction with underground openings in fractured rock. Rock Mech Rock Eng 40:531-561

Kaiser PK, Cai M (2013) Critical review of design principles for rock support in burst-prone ground-time to rethink. In: Potvin Y, Brady B (eds) Ground Support 2013, 13-15 May, Perth, Australian Center for Geomechanics, pp 3-37

Kaiser PK, Maloney SM (1997) Scaling laws for the design of rock support. Pure Appl Geophys 150:415-434

Kaiser PK, McCreath DR, Tannant DD (1996) Canadian rockburst support handbook. Geomechanics Research Centre, Sudbury, p 300

Linkov AM, Durrheim RJ (1998) Velocity amplification considered as a phenomenon of elastic energy release due to softening. In: Rossmanith HP (ed) Proceedings of the 3rd international conference on mechanics of jointed and faulted rock, Vienna, Austria, 6-9 April, Balkema, Rotterdam, pp 243-248

Malmgren L, Nordlund E (2008) Interaction of shotcrete with rock and rock bolts-a numerical study. Int J Rock Mech Min Sci 45:538-553
McGarr A (1997) A mechanism for high wall-rock velocities in rockbursts. Pure Appl Geophys 150:381-391

Mikula PA (2012) Progress with empirical performance charting for confident selection of ground support in seismic conditions. Min Technol 121(4):192-203

Milev AM, Spottiswood SM (2005) Strong ground motion and site response in deep South African mines. J S Afr Inst Min Metall 105(7):515-524

Ortlepp WD (1993) High ground displacement velocities associated with rockburst damage. Rockburst and Seismicity in Mines. In: Young PR (ed) Proceedings of the 3rd international symposium on rockbursts and seismicity in mines, Kingston, Ontario, Canada, 16-18 August, Balkema, Rotterdam, pp 101-106

Potvin Y, Wesseloo J, Heal D (2010) An interpretation of ground support capacity submitted to dynamic loading. Min Technol 119(4):233-245

Pyrak-Nolte LJ (1996) The seismic response of fractures and the interrelations among fracture properties. Int J Rock Mech Min Sci Geomech Abstr 33(8):787-802

Pyrak-Nolte LJ, Myer LR, Cook NGW (1990) Transmission of seismic waves across single natural fractures. J Geophys Res 95(B6):8617-8638

Roberts MKC (1995) Stope and gully support. Final report GAP032. Safety in Mines Research Advisory Committee, Johannesburg, p 123

Roberts MKC, Brummer RK (1988) Support requirements in rockburst conditions. J S Afr Inst Min Metall 88(3):97-104

Shirzadegan S, Nordlund E, Zhang P (2016) Large scale dynamic testing of rock support system at Kiirunavaara underground mine. Rock Mech Rock Eng 49(7):2773-2794

Simser B (2012) Ground support in "Deep" underground mines. https:// www.workplacesafetynorth.ca/sites/default/files/Ground\%20Sup port $\% 20$ in $\% 20$ Deep $\% 20$ Underground\%20Mines.pdf. Accessed 1 Sept 2016

Stacey TR, Rojas E (2013) A potential method of containing rockburst damage and enhancing safety using a sacrificial layer. J S Afr Inst Min Metall 113:565-573

Wagner H (1984) Support requirements for rockburst conditions. In: Gay NC, Wainwright EH (eds) Proceedings of the 1st International symposium on rockbursts and seismicity in mines. The South African Institute of Mining and Metallurgy, Johannesburg, pp 209-218

Yi XP, Kaiser PK (1993) Mechanisms of rockmass failure and prevention strategies in rockburst conditions. In: Young PR (ed) Proceedings of the 3rd international symposium on rockbursts and seismicity in mines, Kingston, Ontario, 16-18 August, Balkema, Rotterdam, pp 141-145

Zhang P, Swan G, Nordlund E (2015) 1D numerical simulation of velocity amplification of $\mathrm{P}$-waves travelling through fractured rock near a free surface. J S Afr Inst Min Metall 115(11):1121-1126

Zhang P, Dineva S, Nordlund E et al (2016) Establishment of experimental sites in three Swedish mines to monitor the in-situ performance of ground support systems associated with mininginduced seismicity. In: Nordlund E, Jones TH, Eitzenberger A (eds) Ground support 2016. Luleå, Sweden, p 14

Zhao XB, Zhao J, Cai JG (2006) P-wave transmission across fractures with nonlinear deformational behaviour. Int J Numer Anal Meth Geomech 30:1097-1112

Zhao XB, Zhao J, Cai JG et al (2008) UDEC modelling on wave propagation across fractured rock masses. Comput Geotech 35:97-104

Publisher's Note Springer Nature remains neutral with regard to jurisdictional claims in published maps and institutional affiliations. 